\title{
Role of Coastal Convection to Moisture Buildup during the South China Sea Summer Monsoon Onset
}

\author{
Wei-Ting CHEN, Chien-Ming WU, Wei-Ming TSAI ${ }^{1}$, \\ Peng-Jen CHEN, and Po-Yen CHEN ${ }^{2}$ \\ Department of Atmospheric Sciences, National Taiwan University, Taiwan
}

(Manuscript received 26 March 2019, in final form 1 September 2019)

\begin{abstract}
In this study, the climatological characteristics of object-based precipitation systems (OPSs) and moisture development are analyzed over the South China Sea (SCS) during the sharp transition of the summer monsoon onset. The satellite-observed statistics of the OPSs showed that over the 20-day pre-onset period, OPSs of small $(<100 \mathrm{~km})$ to medium size $(100-300 \mathrm{~km})$ are active over the lands surrounding the SCS. The pre-onset composite mean shows a basin-scale $(\sim 1000 \mathrm{~km})$ local circulation with anomalous subsidence over the ocean, and ocean convection is mostly suppressed. Over the 20-day post-onset period, large ( $>300 \mathrm{~km})$ OPSs develop over the coastal ocean and contribute to over $60 \%$ of the total precipitation. The number of large OPSs observed significantly increases along with the sharp moisture buildup within 10 days after the onset. The moisture budget suggests that the local contribution from convective vertical mixing is the major moisture source during the first pentad after the onset. The relationship between moisture buildup and convection organization is then examined using a set of idealized cloud-resolving model (CRM) experiments, with a land-ocean configuration approximating the SCS basin. The CRM appropriately represents the observed development of coastal convection. In the noshear environment, a strong basin-scale circulation is formed, which suppresses the ocean moisture development. When large-scale vertical wind shear is imposed to represent the changes of large-scale circulation during the onset pentad, organized convection systems are increased over the coastal ocean and propagate toward the open ocean, accompanied by fast ocean moistening within 5-10 days.
\end{abstract}

Keywords coastal convection; moisture; TRMM; CloudSat; cloud-resolving model

Citation Chen, W.-T., C.-M. Wu, W.-M. Tsai, P.-J. Chen, and P.-Y. Chen, 2019; Role of coastal convection to moisture buildup during the South China Sea summer monsoon onset. J. Meteor. Soc. Japan, 97, 1155-1171, doi: 10.2151/jmsj.2019-065.

Corresponding author: Wei-Ting Chen, Department of Atmospheric Sciences, National Taiwan University, No.1 Sec. 4 Roosevelt Rd, Taipei 10617, Taiwan

1 Present affiliation: Rosenstiel School of Marine and Atmospheric Sciences, University of Miami, Florida, USA

2 Present affiliation: Central Weather Bureau, Taiwan

E-mail: weitingc@ntu.edu.tw

J-stage Advance Published Date: 10 September 2019

\section{Introduction}

The South China Sea (SCS) and Maritime Continent (MC) region is a challenging and important area to study convection multi-scale interactions of the tropical atmosphere. This region is at the heart of the rising branch of both the Hadley circulation and Walker circulation. Surrounded by islands and continents with complex topography, the atmospheric convection systems in the SCS-MC region exhibit prominent diurnal variability, organization, and propagation. The occurrence and organization of convection systems 
can be highly modulated by the large-scale environment associated with seasonal variabilities, such as the monsoon onset, and associated with intraseasonal variabilities, such as the Madden-Julian Oscillation and the boreal summer intraseasonal oscillation.

The SCS-MC coastal region is the occurrence hotspot of highly organized mesoscale convection systems (MCSs), as reported by several intensive observation campaigns (e.g., Houze et al. 1981; Johnson and Priegnitz 1981; Ciesielski and Johnson 2006; Aves and Johnson 2008; Kanamori et al. 2013) and from multi-year statistics of satellite observations (e.g., Williams and Houze 1987; Yang and Slingo 2001; Mori et al. 2004; Nesbitt and Zipser 2003; Ichikawa and Yasunari 2006; Yuan and Houze 2010; Yanase et al. 2017). The large and intensive MCSs associated with the monsoon environment are the major contributors to the region's extreme precipitation (Hamada et al. 2014). From the perspectives of both climate and extreme weather, it is imperative to understand how the coastal convection systems over the SCS$\mathrm{MC}$ respond to large-scale conditions, especially the controlling physical mechanism, and how the current atmospheric model can represent these convection multi-scale interactions. These topics are also the key scientific themes of several intensive international field campaigns over the SCS-MC region, namely, the Years of Maritime Continent (YMC, 2017-2019; see http://www.bmkg.go.id/ymc/ and http://www.jamstec. go.jp/ymc/), the South China Sea Two-Island Monsoon eXperiment (SCSTIMX, 2016-2019; see https:// scstimx.as.ntu.edu.tw/) (Lin et al. 2016), and the Propagation of Intra-Seasonal Tropical OscillatioNs (PISTON, 2018-2019; see https://onrpiston.colostate. edu/).

The environmental water vapor content is important for the development of deep convection. Observational studies indicate that the enhancement of moisture in the low to mid-troposphere favors the development of deep convection, while the drier atmosphere might inhibit its growth (Bretherton et al. 2004; Neelin et al. 2008; Holloway and Neelin 2010; Kuo et al. 2017). The moisture development is considered part of the dynamical systems in which the interactions between convection, environmental water vapor, and atmospheric motions are important in understanding the multi-scale variabilities in the tropics (Yu and Neelin 1994; Raymond and Torres 1998; Sobel and Bretherton 2003; Raymond and Fuchs 2007, 2009; Sugiyama 2009). Using idealized cloud-resolving model (CRM) simulations, Tsai and $\mathrm{Wu}$ (2017) further identified the environment for an increasing probability of the development of large aggregated convection when the environmental column relative humidity $(\mathrm{CRH})$ is greater than $80 \%$ without (and $67 \%$ with) environmental wind shear. Their results also suggested that, after the critical $\mathrm{CRH}$ is met, the degree of aggregation is enhanced with the increase of CRH.

In this study, the moisture buildup and the development of organized convection during the South China Sea summer monsoon (SCSSM) are carefully examined using object-based analysis of satellite observations and CRM simulations. The SCSSM onset is a period when a sharp rainfall burst over the coastal ocean occurs, associated with an abrupt reversal of large-scale low-level winds within 5-10 days (Wang and LinHo 2002; Wang et al. 2009). Chen et al. (2019) identified the precipitation bias associated with the interactions among fast physical processes in a general circulation model (GCM) during the SCSSM onset using the multi-year hindcast approach. Their results showed that during the pre-onset period, the land-ocean precipitation contrast was underestimated, whereas during the post-onset period, the organized coastal convection was not captured. These biases are associated with the underrepresentation of the convection diurnal cycle and the issue of precipitation sensitivity to environmental moisture in physics parameterizations. Therefore, the objective of the current study is to provide a detailed description of the evolution of coastal convection and moisture development during the onset period, emphasizing the importance of the land-sea configuration over the SCS in modulating the response of the coastal convective systems. Section 2 describes the observational data sets and the methodology used to identify object-based precipitating systems (OPSs), as well as the vector vorticity equation cloud-resolving model (VVM). The observed occurrence of OPSs of different size categories and the accompanied moisture buildup during the SCSSM onset period is presented in Section 3. Section 4 shows the VVM simulation results that examine the response of coastal convection to large-scale vertical wind shear, with an idealized land-ocean configuration approximating the SCS basin. A summary and discussion are presented in Section 5.

\section{Data and methodology}

\subsection{Data sets}

The observed precipitation data from the Tropical Rainfall Measuring Mission (TRMM) 3B42 version 7 dataset (Kummerow et al. 2000; Huffman et al. 2010) are analyzed in the present study (1998-2015), which are the microwave, precipitation radar, and infrared 
level-3 rainfall products with 0.25 -degree horizontal spatial resolution and 3-hourly temporal resolution. The vertical distribution of clouds is obtained from the CloudSat R04 2B-GEOPROF cloud mask (Marchand et al. 2008) in our analyses (2007-2015), which is detected by the $94-\mathrm{GHz}$ nadir-pointing cloud profiling radar at a nominal horizontal footprint of $1.4 \mathrm{~km}$ across by $1.8 \mathrm{~km}$ along the track, with 125 vertical bins spanning from the surface to $30 \mathrm{~km}$ altitude and a vertical resolution of $240 \mathrm{~m}$. We note that after 2010 , the $2 \mathrm{~B}$-GEOPROF is available only for daytime overpass owing to the spacecraft battery issues.

The atmospheric temperature, water vapor, and wind fields are based on the 6-hourly European Centre for Medium-Range Weather Forecasts ReanalysisInterim (Dee et al. 2011) with 0.75-degree horizontal resolution (ERA-Int). Daily outgoing longwave radiation (OLR) is taken from the 2.5-degree interpolated data obtained from the National Oceanic and Atmospheric Administration (NOAA) polar-orbiting satellite (Liebmann and Smith 1996). The NOAA Optimum Interpolation Sea Surface Temperature 0.25degree data (NOAA OISST v2.; Reynolds et al. 2002) are used as well.

\subsection{Object-based analysis}

The OPSs are identified over the SCS region with TRMM 3B42. An individual OPS is determined by connecting the spatially contiguous grids with an estimated precipitation intensity $>1 \mathrm{~mm} \mathrm{~h}^{-1}$. The horizontal scale (size) of the OPSs is then defined as the square root of its total areal coverage ( $\mathrm{Su}$ et al. 2019). This allows us to investigate the occurrence location and frequency of OPSs with different sizes.

A similar approach is applied to the CloudSat GEOPROF cloud mask to obtain the vertical cloud object. The cloudy pixels are defined with a cloud mask confidence level $\geq 20$ (Marchand et al. 2008; Hagihara et al. 2010). Contiguous cloudy pixels are connected to obtain cloud objects along the orbit $(x-z$ direction). As we focus on convective clouds in this study, it should be noted that CloudSat may miss the lower part of heavily precipitating clouds due to attenuation of the cloud profiling radar and high thin cirrus clouds due to the detection limit. Considering this, we subjectively define "convective" cloud objects as the cloud objects satisfying both the base height $<3 \mathrm{~km}$ and the top height $>6 \mathrm{~km}$. The size of each convective cloud object is defined by the total $x-z$ area of the connected cloudy pixels.

\subsection{SCSSM onset index}

A rapid transition of wind direction over the SCS is observed during the onset period. Following Wang et al. (2004), the $U_{s c s}$ index is defined as the zonal wind at $850 \mathrm{hPa}$ averaged over $5-15^{\circ} \mathrm{N}, 110-120^{\circ} \mathrm{E}$, illustrating the transition of wind direction during the monsoon onset. The onset date of the SCSSM in an individual year is determined when the following criteria are met: (1) the first pentad after April 25 when $U_{s c s}$ is positive; (2) $U_{s c s}$ in the subsequent four pentads (including the onset pentad) must be positive in at least three pentads; and (3) the accumulative four pentad mean of $U_{s c s}$ is larger than $1 \mathrm{~m} \mathrm{~s}^{-1}$. The climatological mean onset pentad is 27.5 ( mid-May) over 1998-2015, with an interannual standard deviation of 1.7 pentads. In the following analysis, the first day in the onset pentad is considered as day 0 for each year.

To examine the relationships between convection and its large-scale environment during the SCSSM onset, we analyze 20 days before/after the onset date in each year, called the pre-onset (days -20 to -1 ) and the post-onset (days 0 to 19), respectively. The domain of the SCS is defined as $12.5-17.5^{\circ} \mathrm{N}, 110-120^{\circ} \mathrm{E}$, which has the most sensitive precipitation response during the transition of the monsoon. We note that the latitude of the selected domain is different from that of $U_{s c s}$. The $U_{s c s}$ index provides the state of synoptic circulation, and its region is defined by the dominant empirical mode of low-level wind that signifies not only the onset over the SCS but also the entire broadscale East Asia summer monsoon (Wang et al. 2004). As our purpose here is to identify the response of the convective scale phenomenon to the large (synoptic)scale circulation, we use the region that best represents the signal in either scale (i.e., the selected SCS domain for the convective scale and the $U_{s c s}$ region for the synoptic scale) to carry out the composite analysis.

\subsection{Vector vorticity equation cloud-resolving model (VVM)}

The VVM used in this study was developed by Jung and Arakawa (2008), based on the three-dimensional anelastic vorticity equations. A unique aspect of this model is that the model predicts horizontal components of vorticity and diagnoses the velocity by a threedimensional elliptic equation. A bulk three-phase cloud microphysics parameterization, including cloud droplets, ice crystals, rain, snow, and graupel, is applied in this model (Krueger et al. 1995). The topography is implemented through the immersed boundary method in the height coordinate (Wu and Arakawa 2011; Chien and $\mathrm{Wu}$ 2016). The NOAH land surface 
model (Chen et al. 1996; Chen and Dudhia 2001) is implemented as the bottom boundary for surface fluxes (Wu et al. 2019), coupled with the radiation parameterization using the rapid radiative transfer model for GCMs (Iacono et al. 2008). The model has also been used to study the convective aggregation under different vertical wind shear and column moisture conditions (Tsai and Wu 2017), convection organization with heterogeneous land surface fluxes (Wu et al. 2015), the transition of stratocumulus clouds (Tsai and Wu 2016), the precipitation hotspots caused by the afternoon thunderstorm in Taipei basin (Kuo and Wu 2019), and the design of unified parameterization for deep convection (Arakawa and $\mathrm{Wu}$ 2013; Wu and Arakawa 2014).

The details of the land-ocean configuration of the simulated domain in this study are introduced in Section 4. The object-based analysis is also applied to the simulated cloud field, following the method in Tsai and $\mathrm{Wu}$ (2017). The grids with the sum of the cloud water and cloud ice mixing ratio $>10^{-5} \mathrm{~kg} \mathrm{~kg}^{-1}$ are defined as "cloudy", and the spatially contiguous cloudy grids are connected to identify the 3D cloud objects in the simulations. The size of each 3D cloud object is represented by the total volume occupied by the connected cloudy grids.

\section{Results}

\subsection{Object-based statistics during the Pre- and Post- onset of the SCSSM}

Figure 1 illustrates the composite mean precipitation and $850-\mathrm{hPa}$ horizontal circulation over the SCS for the pre- and post-onset periods from years 1998 to 2015. During the pre-onset periods, the low-level easterly circulation dominates over this region and precipitation is significantly suppressed over the ocean. During the post-onset period, the low-level circulation changes to strong southwesterly and heavy precipitation occurs over the ocean. The most significant precipitation enhancement is found near the coastal regions west of the Philippines.

To understand how convective systems of various sizes contribute to pre- and post-onset precipitation, OPSs are identified using the TRMM 3B42 data and classified by the horizontal scale into small $(<100$ $\mathrm{km}$; S), medium (100-300 km; M), and large (> 300 $\mathrm{km}$; L) categories. Figure 2 shows the spatial distribution of the occurrence count for these three categories during the pre- and post-onset periods of 1998-2015. For each OPS identified, all the $3 \mathrm{~B} 42$ grids $\left(0.25^{\circ}\right)$ that are covered (connected) within the object would be counted once. Therefore, in Fig. 2, the occurrence count represents how many times each 3B42 grid had been covered by OPSs of the particular size category. The fractional contribution by each OPS size category to the composite mean total precipitation is shown in Fig. 3. In the pre-onset period, nearly all small OPSs are located over land, with $20-40 \%$ contribution of precipitation; medium OPSs dominate over land and coastal regions, with $60-80 \%$ and $40-60 \%$ contributions, respectively; large OPSs, however, are not likely to develop over this region. It should be noticed that over the ocean, it is difficult for the convective system to develop during pre-onset periods. During the post-onset period, precipitation contributions among the OPSs change dramatically. Large OPSs dominate over the ocean and contribute $60-80 \%$ of the amount of precipitation, even above $80 \%$ in some areas. These results suggest that these large OPSs could play an important role during the transition of the SCSSM.

The vertical cloud frequency profiles (Fig. 4a) and the size distribution of vertical convective cloud objects (Fig. 4b) identified from CloudSat GEOPROF cloud masks are also analyzed for the pre- and post-onset period from years 2007 to 2015 . The cloud frequency profile during post-onset periods is higher by $10 \%$ at all altitudes, and the enhancement of the "top-heavy" structure indicates the occurrences of organized convection with extensive anvil clouds (Houze 2004). According to the areas of along-track vertical cross-sections, the convective cloud objects are also classified into three size groups: $<100 \mathrm{~km}^{2}, 100-1000$ $\mathrm{km}^{2}$, and $>1000 \mathrm{~km}^{2}$. Owing to the differences between TRMM 3B42 and CloudSat in resolution and retrieved targets (rainfall versus vertical cloud), the size of the cloud object cannot be compared directly to the size of the TRMM OPSs. As we require the convective cloud object to have a minimum vertical extent of $3 \mathrm{~km}$, the three size bins would correspond roughly to $<33 \mathrm{~km}, 30-330 \mathrm{~km}$, and $>330 \mathrm{~km}$, respectively, in the horizontal spans of cloud cover. The convective cloud objects in the largest sized bin are associated mostly with large OPSs. The numbers of cloud objects are higher during post-onset than pre-onset for all size categories, but the number of the largest size category increases most significantly, which is qualitatively consistent with the statistics of the TRMM 3B42 OPSs. Note that the number of diagnosed cloud objects is considerably low due to the sampling frequency of CloudSat and the selected domain size. 
(a)

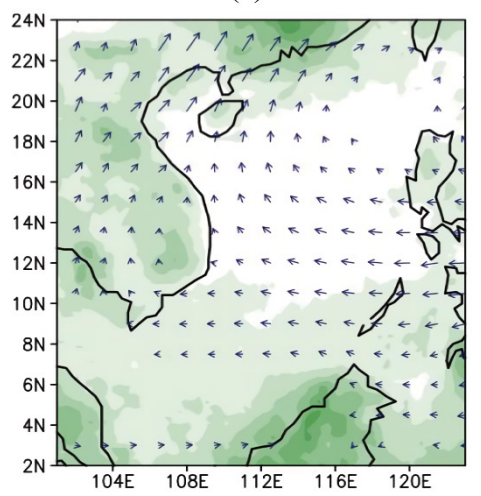

(b)

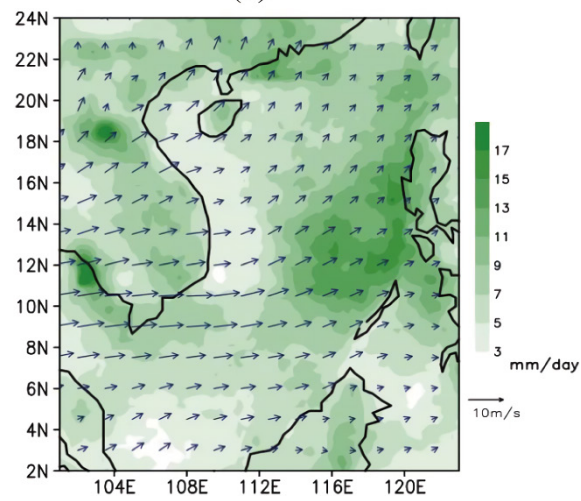

Fig. 1. Climatology of the composite mean TRMM 3B42 precipitation (shading) and ERA-Int $850 \mathrm{hPa}$ circulation (vectors) during the 20 days (a) before and (b) after the onset date of the SCSSM from 1998 to 2015.

(a)
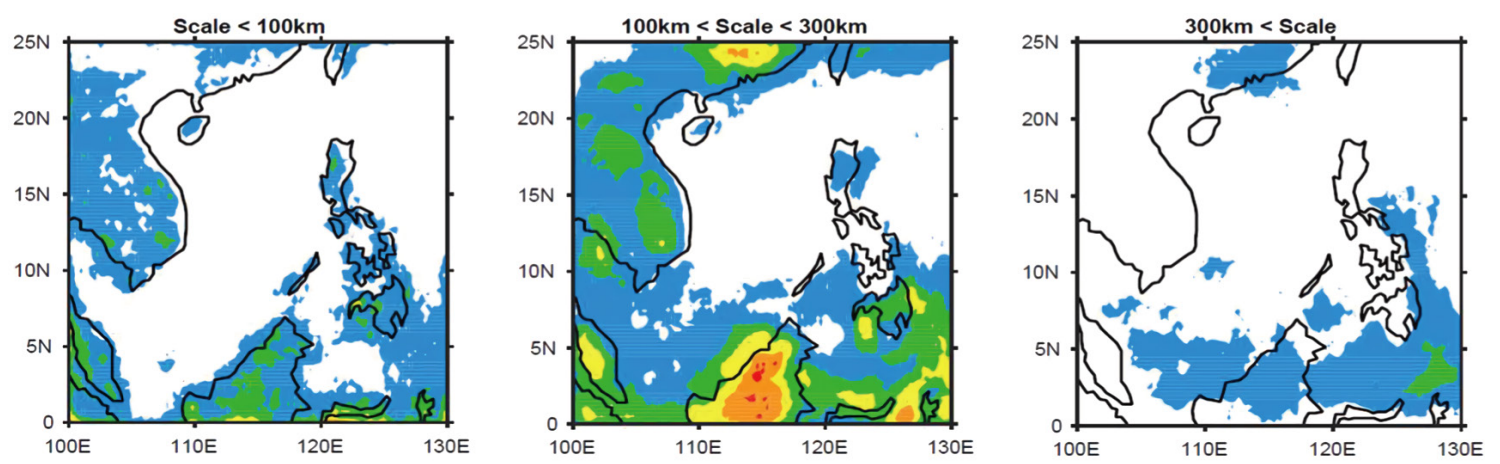

0

50

100

(b)
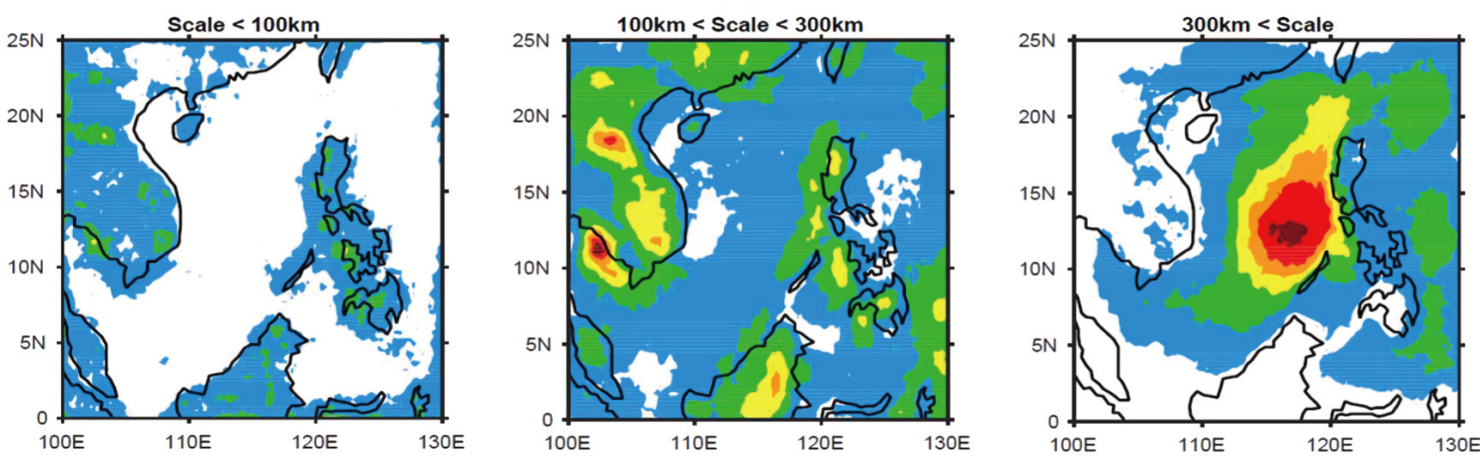

0

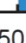

100

150200

250

00

(count)

Fig. 2. Spatial distribution of the occurrence frequency of the three size categories of OPSs in the pre-onset (upper) and post-onset (bottom) periods: (left) small $(<100 \mathrm{~km})$; (middle) medium $(100-300 \mathrm{~km})$; and (right) large $(>300$ $\mathrm{km})$. The size of the OPSs refers to the horizontal scale, which is defined as the square root of the connected precipitating areas. The numbers are the total counts from TRMM 3B42 over 1998-2015 during the 20 days before and 20 days after the onset date defined by the $U_{s c s}$ index every year. 
(a)
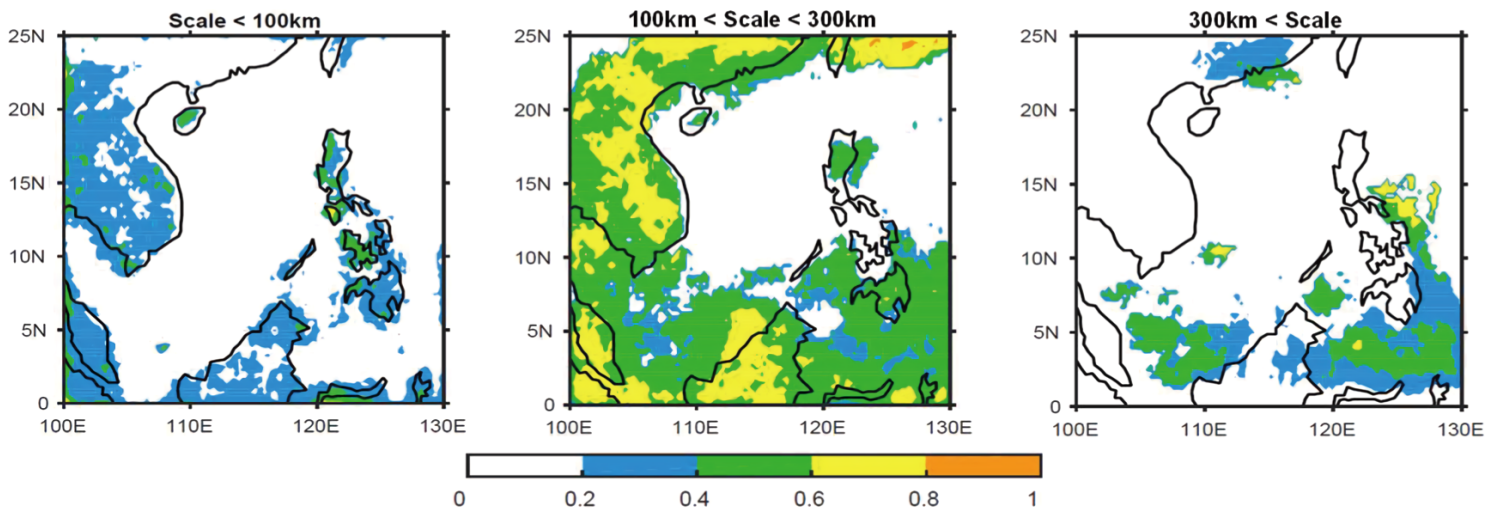

(b)
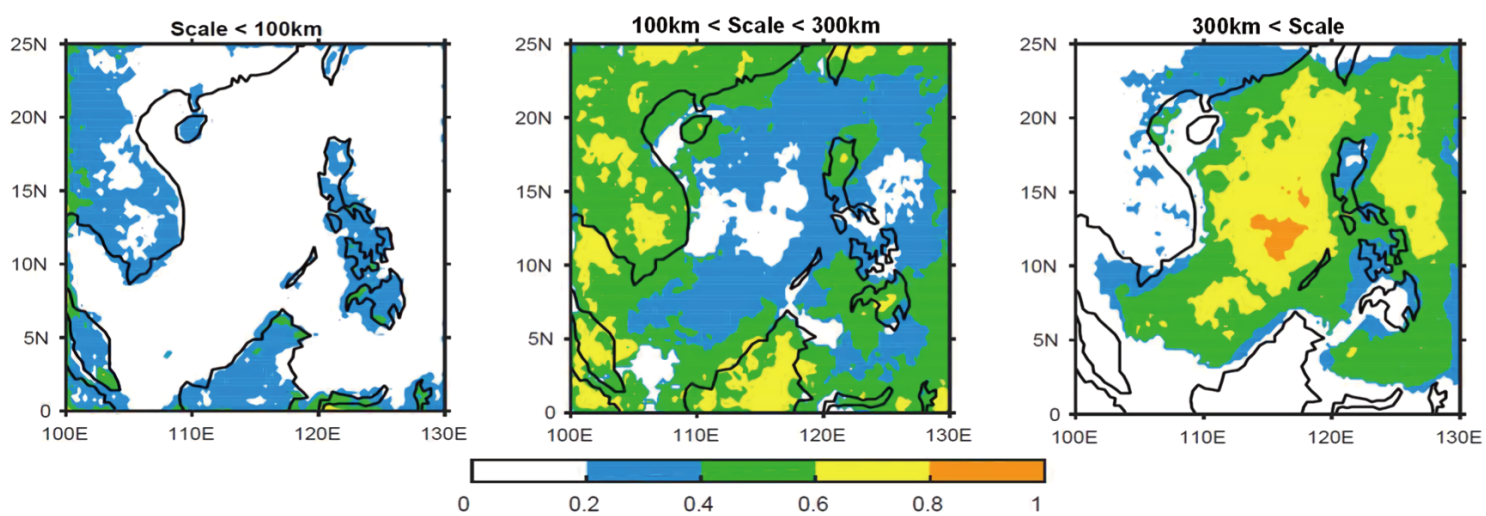

Fig. 3. Similar to Fig. 2, but showing the fractional contribution to total precipitation by the three size categories of OPSs. Note that the definition of the OPSs excludes pixels with a precipitation rate $<1 \mathrm{~mm} \mathrm{~h}^{-1}$, while the total precipitation includes precipitation of all intensity; therefore, in some areas, the fractions of all three categories do not add up to 1 .

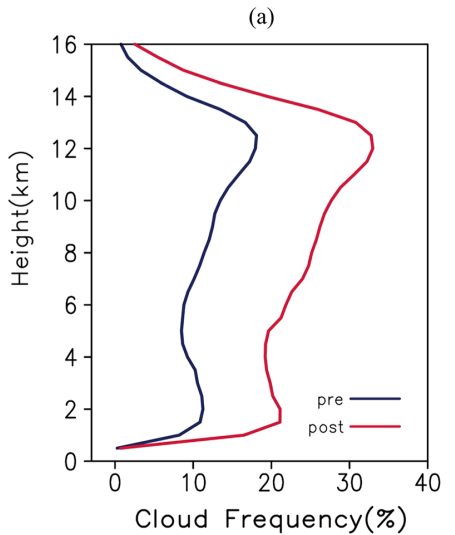

(b)

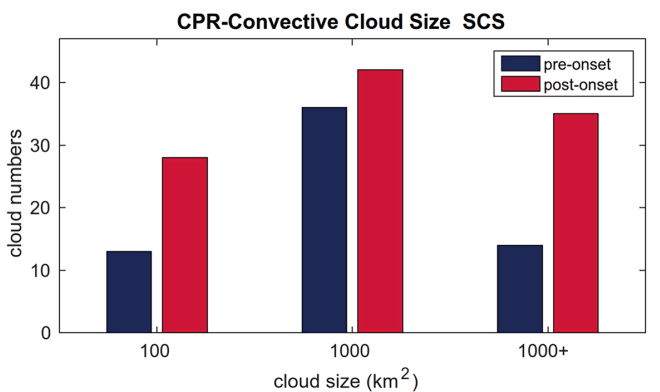

Fig. 4. CloudSat-identified (a) mean cloud frequency profiles and (b) size distribution of convective cloud objects over the SCS ocean $\left(110-120^{\circ} \mathrm{E}, 12.5-17.5^{\circ} \mathrm{N}\right)$ in the pre-onset (blue) and post-onset (red) periods. The vertical cloud frequency is the ratio of cloudy pixels to the total sampled pixels in each vertical bin. Convective cloud objects are the cloud objects with a base height $<3 \mathrm{~km}$ and a top height $>6 \mathrm{~km}$. The size bins correspond to the areas of along-track vertical cross-sections of $<100 \mathrm{~km}^{2}, 100-1000 \mathrm{~km}^{2}$, and $>1000 \mathrm{~km}^{2}$, respectively. 


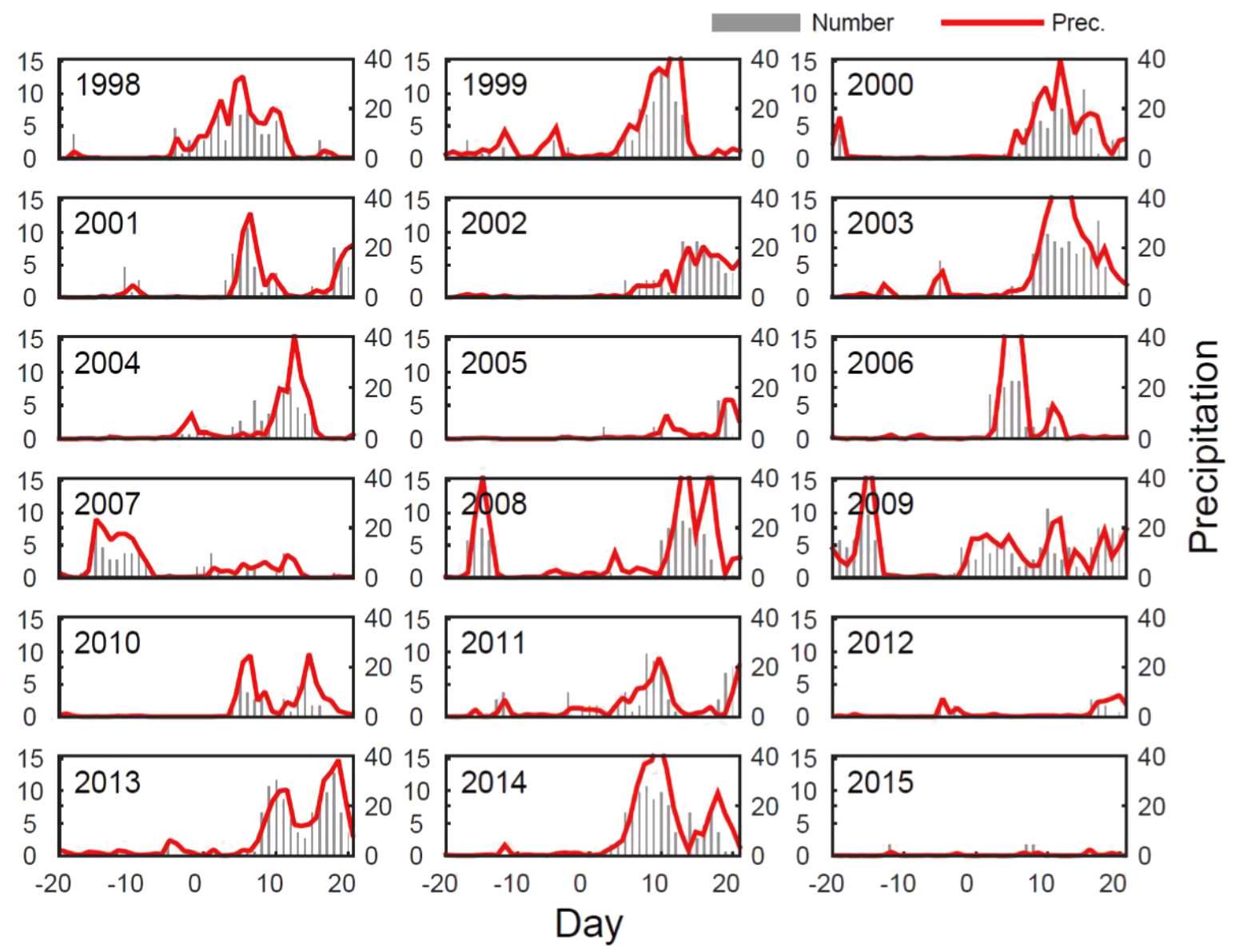

Fig. 5. Evolution of average precipitation (red line) and count number of the organized convection system (gray bars) over the SCS ocean $\left(110-120^{\circ} \mathrm{E}, 12.5-17.5^{\circ} \mathrm{N}\right)$ during the onset period in each year, based on the TRMM 3B42 estimates. The organized convection systems are defined as OPSs larger than $300 \mathrm{~km}$ in the horizontal scale. Day 0 on the $x$-axis represents the first onset date defined by the $U_{s c s}$ index. Twelve years with typical evolution of precipitation activation are subjectively identified: 1998, 2000, 2001, 2002, 2003, 2004, 2006, 2008, 2009, 2010, 2011 , and 2014.

\subsection{Evolution of large OPS number and moisture buildup during the onset period}

The evolution for individual years of the domainaveraged precipitation and large OPS number during the $-/+20$ days of onset, based on the $U_{s c s}$, are presented in Fig. 5. Twelve years with a typical activation pattern of SCSSM onset evolution are selected subjectively for subsequent analyses if an obvious transition of precipitation and moisture occurs near the onset date, namely, 1998, 2000, 2001, 2002, 2003, 2004, 2006, 2008, 2009, 2010, 2011, and 2014. Years with active precipitation or high moisture (ERA-Int column water vapor [CWV] over $50 \mathrm{~mm}$ ) during the pre-onset period (e.g., 1999, 2007, 2013), or years without major precipitation activity throughout the whole onset period (e.g., 2005, 2012, 2015) are excluded. For years 2003, 2008, and 2009, the pre-onset precipitation was contributed by tropical disturbances passing through the SCS, and the column-integrated water vapor remained suppressed $(<50 \mathrm{~mm})$ after the event, so these years are still included in the analysis.

Figure 6 indicates the evolution of precipitation over the land and ocean during the onset period for these selected years. Terrestrial precipitation dominates over the SCS region from 15 days before to the monsoon onset pentad (days -15 to +3 ), while the ocean precipitation starts to rise around 5 days before the onset, sharply increases after day +3 , and becomes comparable to the land precipitation after the onset pentad. The obvious land-ocean precipitation 


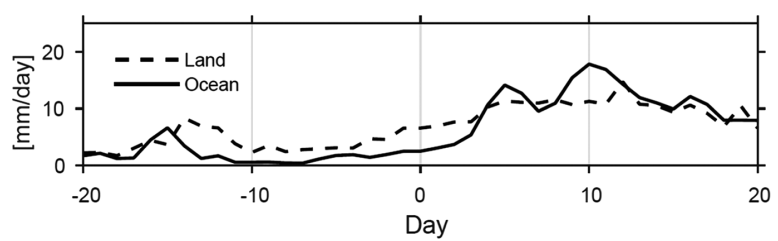

Fig. 6. Evolution of averaged preciptaiton in TRMM 3B42 estimates during the onset period over land (dashed line) and ocean (solid line) regions of the $\operatorname{SCS}\left(108-122^{\circ} \mathrm{E}, 12.5-17.5^{\circ} \mathrm{N}\right)$. The lines show the composite means of the 12 typical activation years.

contrast during the pre-onset period is worthy of a more detailed examination. During the pre-onset period, the climatological mean sea surface temperature (SST) is $302.5 \mathrm{~K}$ for the selected years based on NOAA OISST, providing a favorable thermodynamic condition for the development of convection over the ocean. The land-ocean contrast of precipitation, however, indicates the existence of an additional regional mechanism during the pre-onset period that prevents precipitation over the ocean center, which may be associated with the active convection over the land surrounding the SCS. Figure 7 demonstrated the regional zonal-vertical anomalous circulation over the SCS from ERA-int. During the pre-onset periods of the 12 selected years (Fig. 7a), an anomalous upward motion is located in continents and coastal areas $\left(118-123^{\circ} \mathrm{E}\right.$ and east of $\left.108^{\circ} \mathrm{E}\right)$, while downward motion favors the open ocean in the middle and lower layers. The anomalous circulation further indicates regional subsidence induced by ascending motion over the continents, where convective activities are frequently observed with a diurnal pattern during the pre-onset periods. During the post-onset periods (Fig. $7 \mathrm{~b}$ ), the organized coastal convection over the west coast of the Philippines produces a strong anomalous updraft (downdraft) in the eastern (western) half of the ocean basin and strong subsidence over the western half through the troposphere.

Figure 8 illustrates Hovmöller diagrams of precipitation over the SCS region in 2014, a year nearly free from possible perturbations associated with typhoons, northern frontal systems, and intruding convective systems. During the pre-onset period (days -20 to 0 ), an active diurnal cycle is visible over both coastal regions, while only very weak precipitation occurs over the open ocean. Precipitating systems on the western coast of the Philippines can propagate but retreat to near $118^{\circ} \mathrm{E}$. However, within 5 days after the monsoon (a)

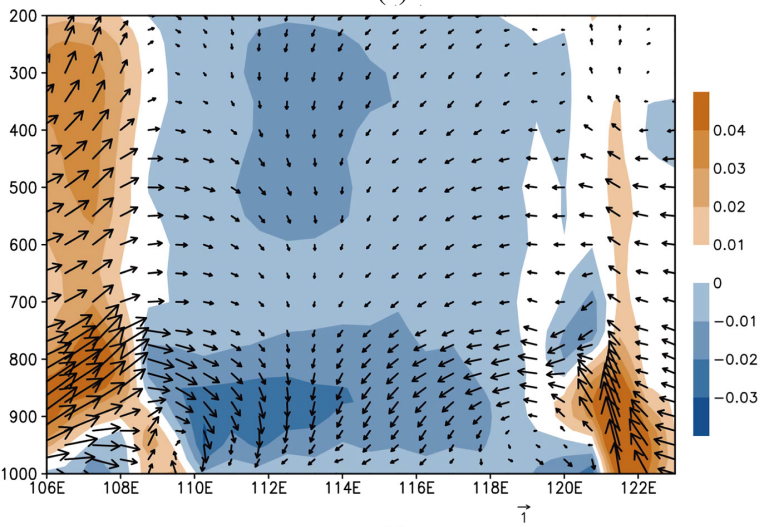

(b)

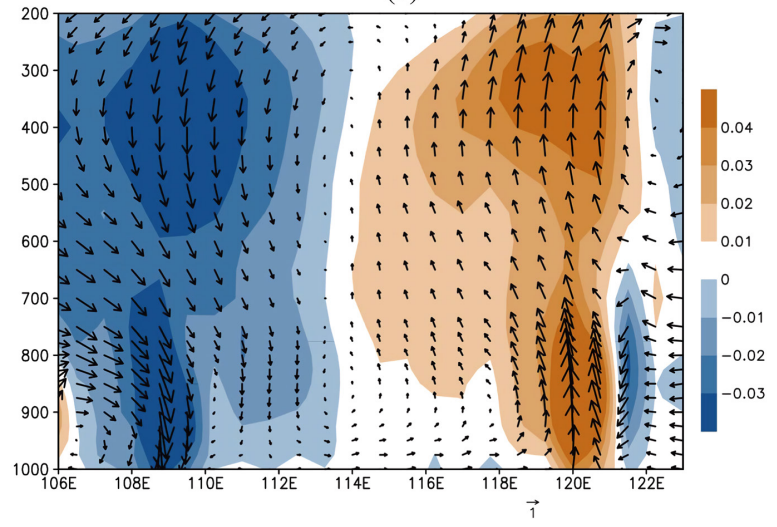

Fig. 7. (a) Pre-onset composite anomalous zonalvertical circulation over the SCS for the 12 typical activation years from ERA-Int. Vectors show the anomalous $u$ and $-\omega \times 50$, and color shading shows anomalous $-\omega$ (in $\mathrm{Pa} \mathrm{s}^{-1}$ ). Only the days when ocean areas exhibit low-level subsidence are conditionally selected (daily mean ERA-Int omega over $110-118^{\circ} \mathrm{E}, 12.5-17.5^{\circ} \mathrm{N}<0.005$ $\mathrm{Pa} \mathrm{s}^{-1}$ for all levels between 1000 and $500 \mathrm{hPa}$; 140 of the total 240 days [58 \%] during the preonset period satisfy such criteria). (b) Similar to (a), but for the post-onset composite without conditional sampling by subsidence (total 240 days). The zonal mean anomaly of $u$ and omega are computed as follows: first, the vertical profiles are averaged meridionally over $12.5-17.5^{\circ} \mathrm{N}$ at each longitude; then, the domain mean vertical profile over $106-123^{\circ} \mathrm{E}, 12.5-17.5^{\circ} \mathrm{N}$ is subtracted to obtain the anomalous profile at each longitude.

onset, precipitation evolves quickly to high intensity there, and these precipitating systems are able to progress further with more extensive coverage with intensity above $20 \mathrm{~mm} \mathrm{day}^{-1}$, and heavy precipitation 


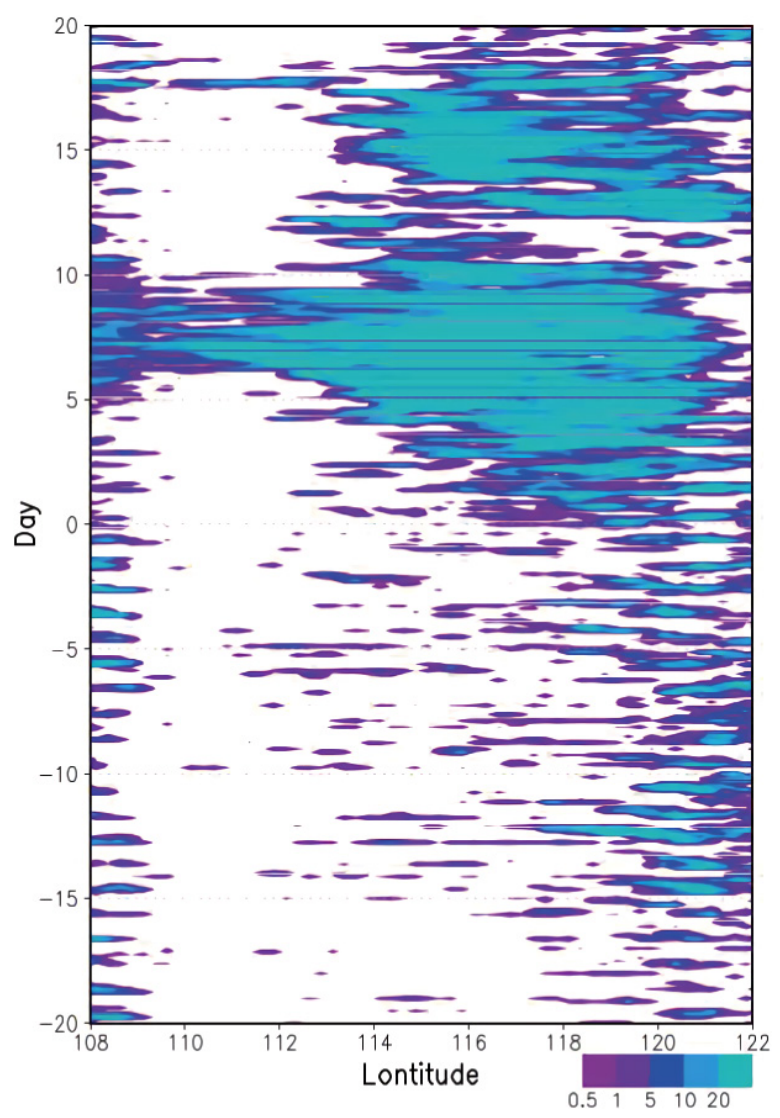

Fig. 8. Hovmöller diagrams of zonal precipitation distribution over the SCS from TRMM 3B42 during the \pm 20 -day onset period in the year 2014 . Day 0 (onset date) corresponds to June 5, 2014.

occurs eventually over the entire open ocean during the post-onset period. As presented in Section 3.1, the systems reaching the open ocean are well organized and dominate the contribution of rainfall there.

The evolution of the daily large OPS number, NOAA OLR, and ERA-Int CWV over the ocean are shown in Fig. 9 for the selected years, along with their composite means. A sharp increase of large OPSs and a decrease in OLR after the onset date are observed and continue for 5-10 days. The moisture buildup is evident near the onset date where the CWV is around $45 \mathrm{~mm}$ in the pre-onset period and then rises sharply to $60 \mathrm{~mm}$ within 10 days after the onset.

The increasing occurrence of large OPSs is accompanied by strong moisture buildup. A budget analysis of vertically integrated moisture averaged over the onset pentad (days 0 to +4 ) and over the SCS ocean (the same domain as in Fig. 9) is carried out, which (a)

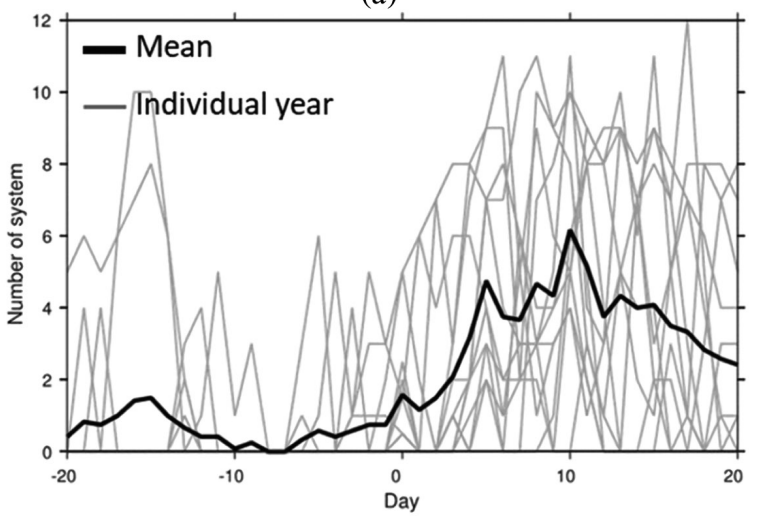

(b)

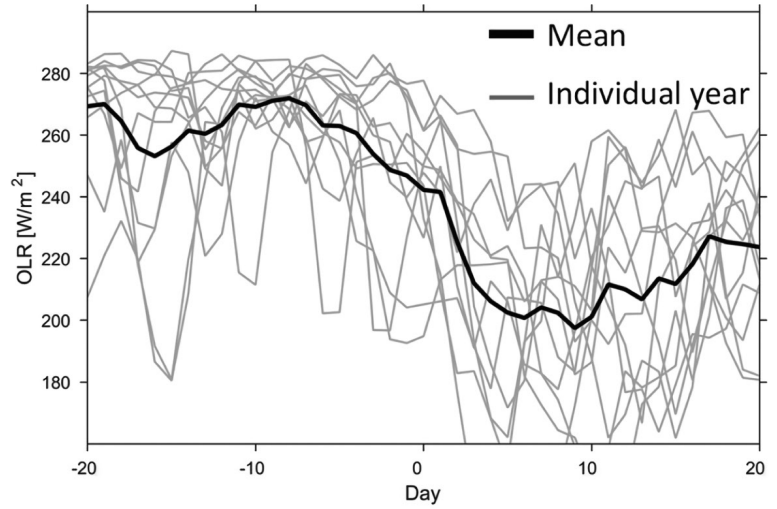

(c)

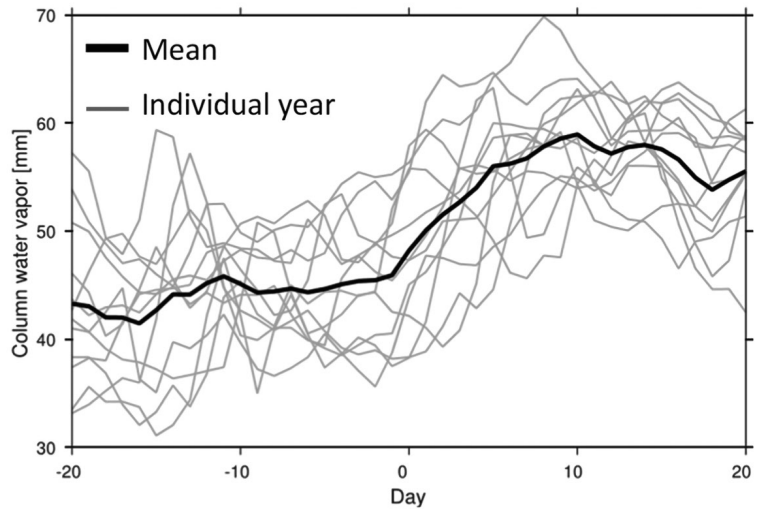

Fig. 9. Evolution of (a) the large OPS number in TRMM 3B42, (b) NOAA OLR, and (c) ERA-Int CWV averaged over the SCS ocean $\left(110-120^{\circ} \mathrm{E}\right.$, $\left.12.5-17.5^{\circ} \mathrm{N}\right)$ during the onset period of the typical activation years listed in Table 2. Black lines show the composite mean of the 12 typical activation years (see caption of Fig. 5), while gray lines show the evolution for individual years. 
can be written as (Chou and Neelin 2004; Chou et al. 2009; Lo and Famiglietti 2011)

$$
\left\langle\frac{\partial q}{\partial t}\right\rangle=(E-P)-\langle V \cdot \nabla q\rangle-\left\langle\omega \frac{\partial q}{\partial p}\right\rangle,
$$

where $q$ is specific humidity, $E$ is evapotranspiration, $P$ is precipitation, $V$ is horizontal winds, $\omega$ is pressure velocity, $p$ is pressure, and \langle\rangle represent a mass integration throughout the troposphere. All the parameters in the budget analysis are taken from ERA-Int, including precipitation. The left-hand side of Eq. (1) is thus the tendency of the CWV. The budget shows that during this strong moistening pentad, the major column moisture source is the vertical transport within the analyzed domain of the SCS ocean $\left(-\left\langle\omega \frac{\partial q}{\partial p}\right\rangle=\right.$ $\left.+6.37 \mathrm{~mm} \mathrm{~d}^{-1}\right)$. On the other hand, the large-scale horizontal moisture convergence at the same period is weak $\left(-\langle V \cdot \nabla q\rangle=-0.07 \mathrm{~mm} \mathrm{~d}^{-1}\right)$. The moistening is balanced mainly by the sink of $E-P\left(-4.57 \mathrm{~mm} \mathrm{~d}^{-1}\right)$.

We note that the SCSSM onset each year is highly influenced by synoptic weather. Therefore, in this section, we rely on the composite analysis to average out the synoptic "noise" in the observations so that the climatological features during the onset period can be identified, including the following:

- The diurnal terrestrial convection is active during the pre-onset stage; the updraft associated with the land convection and the subsidence suppressing the ocean precipitation suggests the existence of a basin-scale local circulation. (Here the basin-scale refers to the width of the SCS plus the surrounding land/islands, which is $\sim 1000 \mathrm{~km}$.)

- With the quick transition of low-level winds to westerlies, the number of large convective systems increases over the coastal region of the Philippines. These coastal systems are triggered diurnally, but their propagation into the open ocean becomes more extensive day by day.

- The increase of large coastal OPSs during the onset pentad is accompanied by fast column moistening over ocean. Vertical transport by local convection is the dominant process to the strong moisture buildup. Based on the above observational evidence, we hypothesize that

(1) The coastal organized convection plays an essential role in the moisture buildup over the SCS. Without the organized convection, the land convection will dominate and build up a basin-scale local circulation, thus suppressing the ocean convection.

(2) The increasing occurrence of the organized coastal convection can modulate the basin-scale circulation and build up the moisture over the SCS.

To examine the above hypotheses, we design a set of idealized CRM simulations in the next section.

\section{Idealized VVM simulations}

We perform idealized VVM simulations with the land-ocean configuration to further investigate the development of coastal convection and its relationship with the moisture buildup. The idealization focuses on the basin-scale circulation over the SCS, as shown in Fig. 10. A triangle-shaped mountain (128 km wide, 1 $\mathrm{km}$ high, parallel to the coastline) is imposed over the $256-\mathrm{km}$ flat land area so that the coastal convection is geographically locked over the ocean. With the periodic boundary conditions, the ocean (768 km wide) is bounded in the east and west by the same land areas, a proxy of the SCS bounded by the Philippines and Indochina. Sensitivity experiments show that without the mountains, the convection propagates from land to sea easily, interfering with the development of coastal convection. The rest of the model settings are as follows: the domain size is $1024 \mathrm{~km}(x$, east-west $) \times$ $512 \mathrm{~km}$ ( $y$, north-south), with a horizontal resolution of $2 \mathrm{~km}$. This idealized setup over the SCS provides a useful framework to study the development of coastal convection. By turning on/off the large-scale vertical wind shear, the causal relationships between the moisture buildup and the organized convection can be evaluated.

Two experiments are performed in this study: in the "shear" experiment, a low-level wind shear with $-2.5 \mathrm{~m} \mathrm{~s}^{-1} \mathrm{~km}^{-1}$ is imposed below $2 \mathrm{~km}$, with a $5 \mathrm{~m} \mathrm{~s}^{-1}$ westerly wind at the surface to represent the largescale vertical wind shear during the onset pentad. Above $2 \mathrm{~km}$, the wind decreases gradually to $-1 \mathrm{~m} \mathrm{~s}^{-1}$ at around $4 \mathrm{~km}$ and is kept constant toward the model top. On the other hand, in the "no-shear" experiment, a uniform $3 \mathrm{~m} \mathrm{~s}^{-1}$ southerly wind at all levels is imposed, representing no change of large-scale circulation. The southerly wind is added so that the surface fluxes over the ocean remain close to reality. With no background wind, the ocean becomes too dry (subsidence plus no latent heat from the ocean). By comparing the two experiments, the role of coastal convection in the moisture buildup over the SCS can be evaluated. Both experiments were integrated for 10 days after spin-up. The SST is fixed at $302.5 \mathrm{~K}$, which is the climatological mean of the 12 typical onset years selected above, based on the NOAA OISST. The land surface type is represented by evergreen broadleaf forests, using the NOAH land model. A stretching grid is used in 


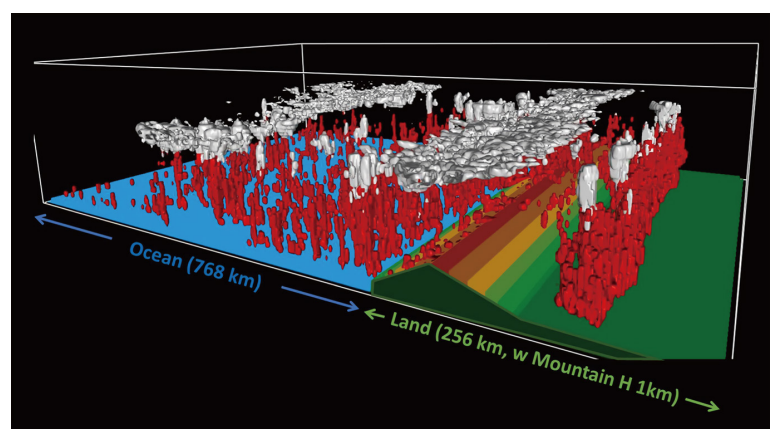

Fig. 10. Land-ocean configuration of the idealized VVM simulations. Length ( $y$-direction) $=512$ $\mathrm{km}$; ocean width $=768 \mathrm{~km}, \mathrm{SST}=302.5 \mathrm{~K}$; land width $=256 \mathrm{~km}$, surface type $=$ evergreen broadleaf; mountain range height $=1 \mathrm{~km}$ and width $=$ $128 \mathrm{~km}$. A periodic boundary is applied in both $x$ - and $y$-directions. A snapshot of the simulated cloud field is shown by the red $\left(q_{c}>10^{-5} \mathrm{~kg} \mathrm{~kg}^{-1}\right)$ and white $\left(q_{i}>10^{-5} \mathrm{~kg} \mathrm{~kg}^{-1}\right)$ iso-surfaces for liquid and ice clouds, respectively.

the vertical direction with a grid size of $100 \mathrm{~m}$ near the surface and $1000 \mathrm{~m}$ near the model top around $30 \mathrm{~km}$. The model is initialized with horizontally uniform thermodynamic profiles from the ERA-Int data averaged over the pre-onset period. The model is first spun up for 3 days before the two experiments are performed.

Figure 11a shows the zonal-vertical distribution of moisture (contour), vertical motion (vectors), and cloud fraction (shading) in the no-shear experiment, averaged along the $y$-direction of the domain during the last 5 days of the simulation. With the periodic boundary condition, the western land in Fig. 11 is a duplicate of the eastern land. We plotted the domain this way to approximate the land-ocean distribution of the SCS basin. The deep clouds and the associated updrafts develop mainly over the mountain areas, and the anvil areas extend to the flat land. Over the coastal ocean on the eastern and western sides of the basin, deep clouds also occur, but are limited near the coastlines. Further into the ocean center, the cloud fraction is low $(\sim 10 \%$ ) and shallow (below $4 \mathrm{~km})$, and strong subsidence occurs from the upper atmosphere all the way to the lower levels. Corresponding to the convection distribution, a strong land-ocean moisture gradient is formed, with enhanced moisture over the land and suppressed moisture over the ocean center. The averaged profile of subsidence velocity over the ocean (Fig. 11b) shows subsiding motion through most levels. The basin-scale circulation and strong land-ocean contrast in convection and moisture in the no-shear simulation are consistent with the pre-onset observations presented in Section 3.

Figures $11 \mathrm{c}$ and $11 \mathrm{~d}$ show the results in the shear simulation. Imposing a low-level westerly shear leads to the development of strong, deep convection with a strong updraft over the windward coast (eastern side of the ocean), with the anvil extending to the ocean center. The deep convection over the land is now more confined to the mountain areas. The vertical motion and moisture distribution characterize an east-west gradient over the ocean, with an enhancement in the eastern half. The averaged oceanic vertical motion is weak, with an updraft in the mid-levels and subsidence at low and high levels.

Figure 12 presents the size (volume) distributions of the 3D cloud objects collected over the eastern half of the ocean in the two experiments. The shear simulation contains more large-sized (volume $>10^{3} \mathrm{~km}^{3}$ ) clouds, indicating the enhancement of convection organization under the shear environment, which is consistent with the increasing presence of large OPSs over the Philippines coast during the post-onset of the SCSSM.

The Hovmöller diagrams of oceanic precipitation for these two simulations from days 1 to 5 are shown in Fig. 13. For the no-shear case (Fig. 13a), a clear diurnal cycle over both coastal regions is simulated, a pattern similar to the observed pre-onset composite in the year 2014 shown in Fig. 13c. Strong suppression of precipitation can be found over the open ocean. Even though precipitating systems are generated near the coastlines, they cannot propagate to the open ocean, and strong precipitation is therefore confined within $150 \mathrm{~km}$ offshore. Note that as the observed coastal diurnal cycle exhibits day-to-day variations (Fig. 8), the 20-day pre-onset period is averaged into 5-daylong composites to provide more relevant comparisons with the idealized simulations (see caption for details). For the shear case (Fig. 13b), the magnitude of precipitation over the western side of the ocean reduces, while precipitating systems on the eastern side of the ocean are still triggered diurnally, and propagate further and further into the open ocean each day; by day 5 , heavy precipitation can occur over the eastern half of the ocean basin. The response of the simulated coastal convection to the imposed low-level wind shear resembles the observed evolution during the onset pentad in the year 2014 (Fig. 13d).

Given the differences in local circulation and convection population and propagation, the moisture 
(a)

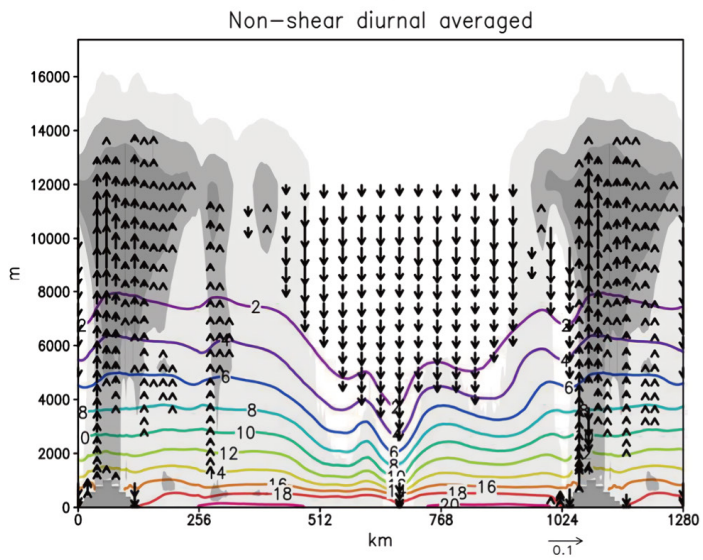

(c)

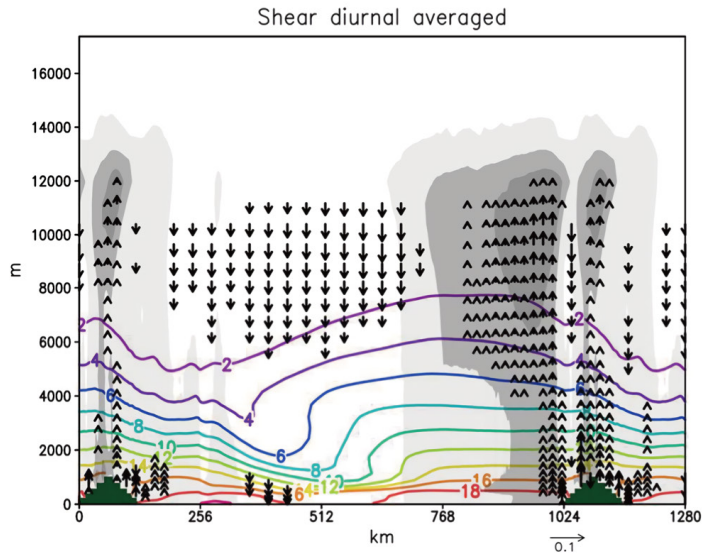

(b)

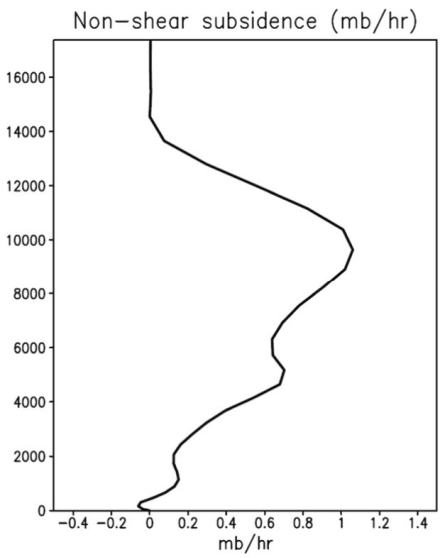

(d)

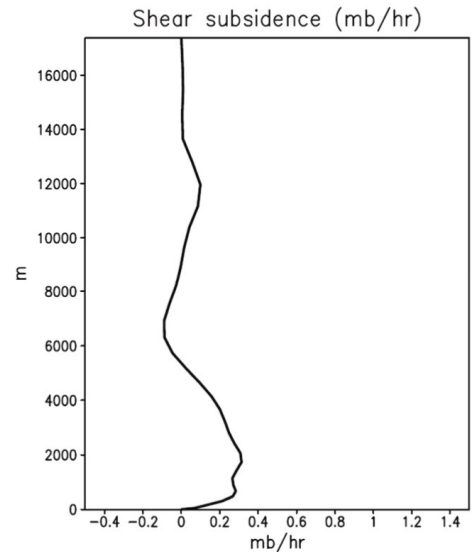

Fig. 11. (a) Zonal-vertical distribution of the cloud fraction (shading; at intervals of $10 \%$ ), vertical velocity (vectors; in $\mathrm{m} \mathrm{s}^{-1}$ ), and water vapor mixing ratio (contour; in $\mathrm{g} \mathrm{kg}^{-1}$ ), meridionally averaged over $y=0-512 \mathrm{~km}$. Only the vertical velocity with a magnitude greater than $0.005 \mathrm{~m} \mathrm{~s}^{-1}$ is plotted, and the downdraft is multiplied by 5 for clearer visualization. (b) Averaged profile of subsidence velocity over the ocean (averaged over $x=256-1024 \mathrm{~km}$, $y=0-512 \mathrm{~km}$ ); positive values correspond to subsidence. Results are averaged daily over the last 5 days of the no-shear simulation. (c) and (d) are similar to (a) and (b), but for the shear simulation.

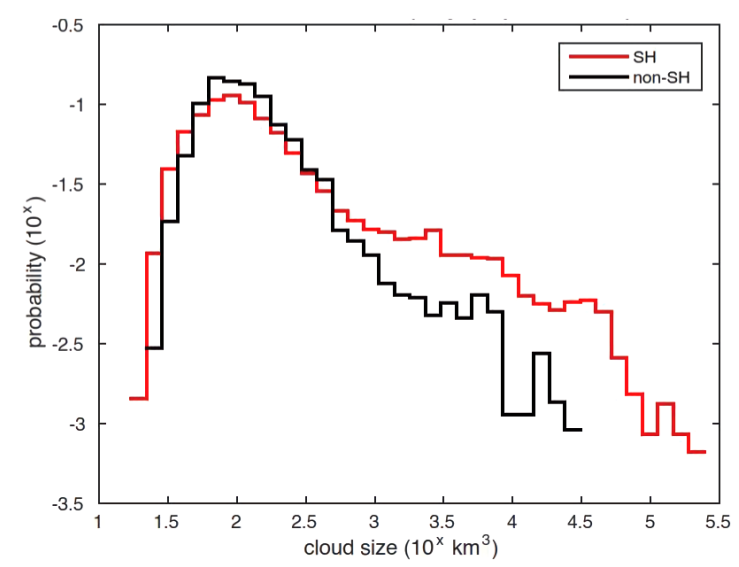

Fig. 12. Probability distribution of convective cloud size in no-shear (black) and shear (red) experiments over the eastern half of the ocean $(x=640-1024 \mathrm{~km}$, $y=0-512 \mathrm{~km}$ in Fig. 11a) during the last 5 days of simulations. Note that both the $x$-axis and $y$-axis are in logarithmic scale. 
(a)

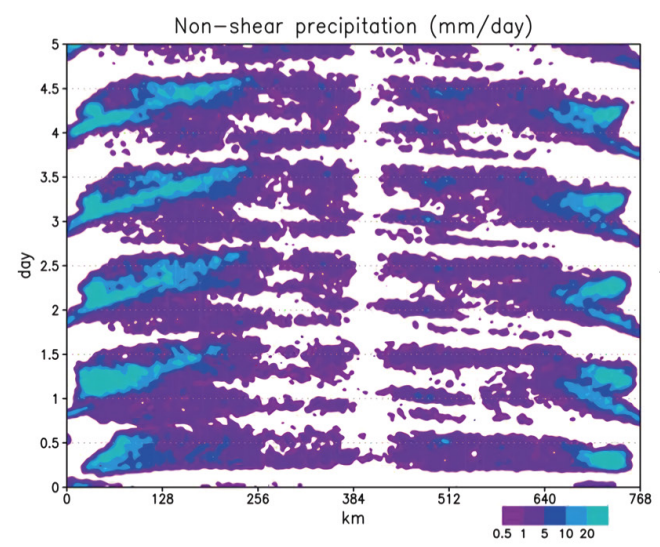

(c)

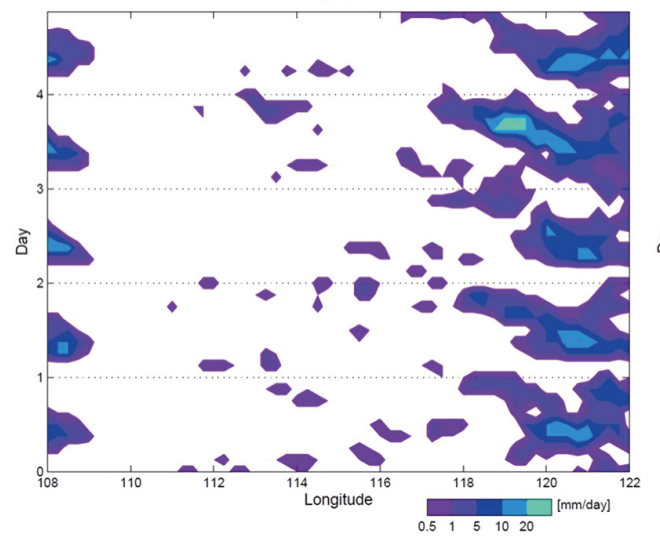

(b)

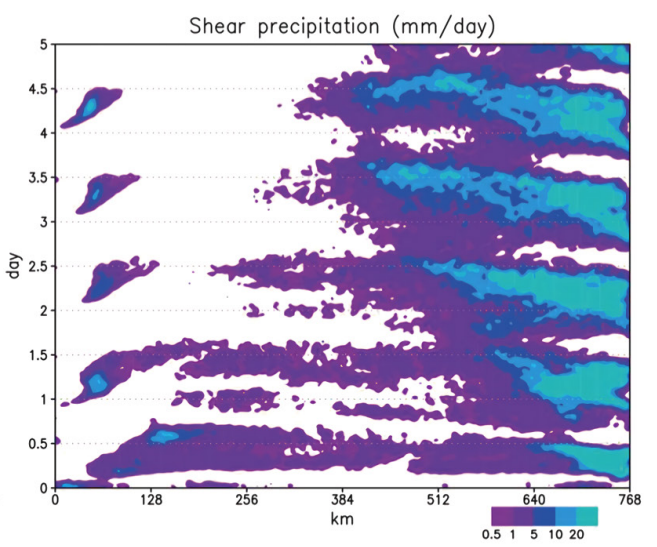

(d)

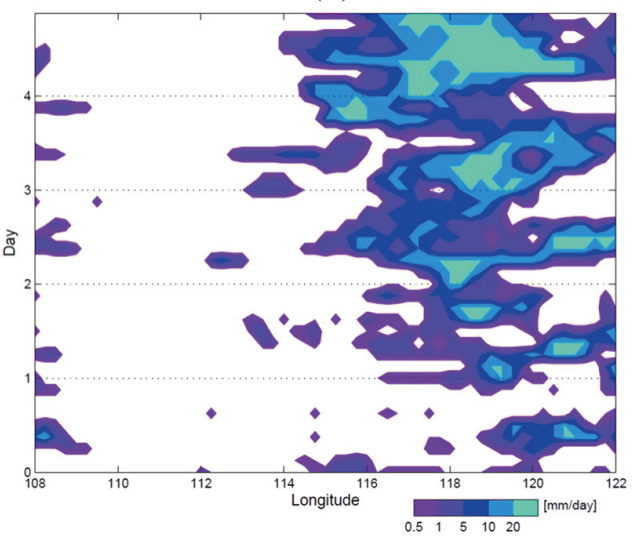

Fig. 13. Hovmöller diagrams of zonal precipitation distribution over the ocean in the (a) no-shear and (b) shear CRM simulations from days 1 to 5 ( $x=256-1024 \mathrm{~km}$ in Fig. 11a, averaged along the $y$-axis); from TRMM 3B42 observations in the year 2014 over the SCS in (c) 5-day composites during pre-onset periods (separating the 20 days into 5-day-long segments for composites, e.g., day 0 composite = average of 1st, 6th, 11th, and 16th days of the pre-onset period, and so on) and (d) 5 days during the onset pentad.

buildup over the ocean shows a drastic contrast between the two experiments (Fig. 14). The average CWV over the open ocean in the no-shear experiments is maintained at around $43-47 \mathrm{~mm}$ in the 10-day integration, while in the shear experiment, the CWV increases sharply from 43 to $52 \mathrm{~mm}$ in the first 5 days and remains around $53 \mathrm{~mm}$ steadily after day 6. The quick moistening from days 1 to 5 in the shear experiment is consistent with the continuous intrusion of coastal propagating systems to the open ocean, and our simulation indicates that it takes around 5-10 days for the ocean to transition from a convectively suppressed state to an active state. This time scale is similar to the composite evolution of the CWV in Fig. $9 \mathrm{c}$ in which significant moistening occurs within 10 days after the large-scale low-level winds switch to westerly.

\section{Summary and discussion}

This study investigates the detailed evolution of convective activities and moisture buildup during the SCSSM onset by applying object-based composite analyses on satellite precipitation and vertical cloud mask observations over the SCS, as well as carrying out idealized CRM simulations with the land-ocean configuration. The overall results highlight the essential role of propagating coastal organized systems to the ocean moistening during the onset pentad, and the impact of land convection on the basin-scale circulation. The patterns of the diurnal cycle, precipi- 


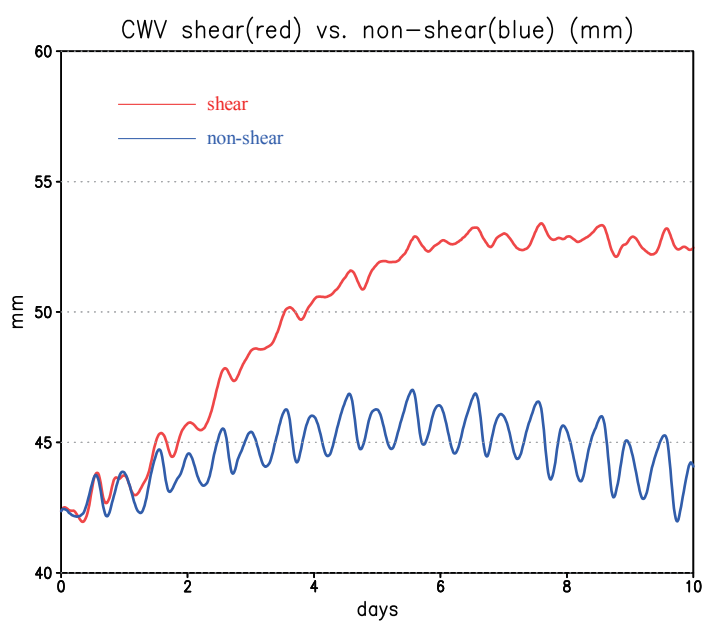

Fig. 14. Time evolution of the CWV over open ocean areas $(x=448-832 \mathrm{~km}$ in Fig. 11a) in the VVM simulation without vertical wind shear (blue line) and with vertical shear (red line).

tation distribution, and ocean moistening in the VVM simulations capture the key features in the observed climatology in the absence of the disturbance from the synoptic scale weather. The results suggest the potential need of improving the representation of organized coastal systems in GCMs to capture a more realistic pattern of the monsoon onset, as suggested in Chen et al. (2019). The organization and propagation of the coastal systems can be sensitive to the strength and vertical distribution of vertical winds, as observed during the SCSMEX field campaign (Johnson et al. 2005). The convection development can also depend on the initial (pre-onset) moisture level and hence the SST. In the future, systematic sensitivity experiments on these large-scale conditions will be carried out with the same land-ocean configuration to investigate their effects on the ocean moistening time scale.

Previous studies have shown that the boundary layer (BL) gravity waves from the diurnal cycle over land (e.g., Mapes 2003a, b; Warner et al. 2003; Hassim et al. 2016; Yokoi et al. 2017) and the land-sea breeze circulation (e.g., Houze et al. 1981; Mori et al. 2004; Wapler and Lane 2012) may play important roles in triggering the offshore propagating systems (or their precursor convection) over the coastal ocean. In our simulations, the propagation speed of the weak precipitation $\left(<5 \mathrm{~mm} \mathrm{~h}^{-1}\right)$ into the open ocean in Fig. 13 is close to the phase speed of the BL gravity waves $\left(\sim 14 \mathrm{~m} \mathrm{~s}^{-1}\right)$ in the current model configuration. After examining the $\mathrm{BL}$ temperature perturbation, we found that these weak convections are triggered by the $\mathrm{BL}$ gravity waves from the land convection (peaks in the afternoon) and coastal convection (peaks in the early morning) on both sides of the coastline. Therefore, the weak precipitation exhibits a semi-diurnal variation, particularly in the no-shear simulation, which coincides with the semi-diurnal variation of the CWV (Fig. 14). In the shear simulation, the propagation of the coastal organized convection is slower than the weak precipitation. If estimated using the envelope of heavy rainfall $\left(>10 \mathrm{~mm} \mathrm{~h}^{-1}\right)$ in Fig. 13, the propagation speed is $\sim 4 \mathrm{~m} \mathrm{~s}^{-1}$, generally within the range of the near-shore propagating convection observed by Mori et al. (2004) and Yokoi et al. (2016) over the western coast of Sumatra. The difference in the propagation speeds between the faster front of weak precipitation and the slower near-shore heavy precipitation is also consistent with the observations.

In the future, by changing the land surface type to modulate the intensity and timing of the diurnal peak over land, the response of the propagating coastal convection can be tested and analyzed from the VVM output. Considering the sensitivity of the current results to the horizontal resolution of CRM, a test simulation has been carried out by increasing the horizontal resolution to $500 \mathrm{~m}$. The preliminary results suggest that qualitatively the dependence on the environment shear still holds, but the moistening time scale varies. We speculate that this is related to the variability of cold pool captured in the high-resolution $(500 \mathrm{~m})$ simulations, and the cold pools effects will be analyzed and discussed with more details in a study following the present work.

The present study identifies the close relationship between coastal convection and ocean moisture buildup over the SCS. Similar processes may also occur around other coastal areas exhibiting strong monsoon transition or intraseasonal variabilities, such as the Bay of Bengal, the western coast of the Indian continent, major islands over the MC, and the Timor Sea and the Arafura Sea over northern Australia. These coastal regions are the hotspots where favorable environments for aggregated convection occur frequently, as identified in Fig. 13 of Tsai and Wu (2017) using a CWV $>45 \mathrm{~mm}$ and a critical vertical wind shear $>2$ $\mathrm{m} \mathrm{s}^{-1}(100 \mathrm{hPa})^{-1}$ within low-level layers (1000-850 $\mathrm{hPa}$ ). In the observational analysis of Hamada et al. (2014), extreme rainfall over these regions is contributed mainly by convection systems that are both large in size and strong in intensity. In the future, the framework of idealized CRM simulations with the land-ocean configuration in the current study can be 
utilized, with appropriate adjustments to the scale of topography and large-scale conditions, to study the relationship between organized coastal convection and moisture transition in these coastal areas.

\section{Acknowledgments}

This work is supported by the Ministry of Science and Technology of Taiwan (WT Chen and PJ Chen: MOST108-2111-M-002-024; CM Wu, WM Tsai, and PY Chen: MOST 107-2111-M-002-010-MY4). The observation and reanalysis data sets were downloaded from the following sources:

- TRMM 3B42 (1998-2015): https://pmm.nasa.gov/ data-access/downloads/trmm (accessed Mar 21, 2019)

- CloudSat GEOPROF (2006-2015): http://www. cloudsat.cira.colostate.edu/order-data (accessed May 21, 2019)

- NOAA Interpolated OLR (1998-2015): http://www. esrl.noaa.gov/psd/data/gridded/data.interp_OLR. html (accessed Mar 21, 2019)

- NOAA OISST v2 (1998-2015): http://www.esrl. noaa.gov/psd/data/gridded/data.noaa.oisst.v2.highres. html (accessed Mar 21, 2019)

- ERA-Int (1998-2015): http://apps.ecmwf.int/datasets/data/interim-full-daily/levtype $=\mathrm{sfc} / \quad$ (accessed Mar 21, 2019)

The VVM simulations are available for online sharing upon request, due to the large volume of data sets and limited disk space.

\section{References}

Arakawa, A., and C.-M. Wu, 2013: A unified representation of deep moist convection in numerical modeling of the atmosphere. Part I. J. Atmos. Sci., 70, 1977-1992.

Aves, S., and R. H. Johnson, 2008: The diurnal cycle of convection over the northern South China Sea. J. Meteor. Soc. Japan, 86, 919-934.

Bretherton, C. S., M. E. Peters, and L. E. Back, 2004: Relationships between water vapor path and precipitation over the tropical oceans. J. Climate, 17, 1517-1528.

Chen, F., and J. Dudhia, 2001: Coupling an advanced land surface-hydrology model with the Penn State-NCAR MM5 modeling system. Part I: Model implementation and sensitivity. Mon. Wea. Rev., 129, 569-585.

Chen, F., K. Mitchell, J. Schaake, Y. Xue, H.-L. Pan, V. Koren, Q. Y. Duan, M. Ek, and A. Betts, 1996: Modeling of land surface evaporation by four schemes and comparison with FIFE observations. J. Geophys. Res., 101, 7251-7268.

Chen, W.-T., C.-M. Wu, and H.-Y. Ma, 2019: Evaluating the bias of South China Sea summer monsoon precipitation associated with fast physical processes using climate model hindcast approach. J. Climate, 32, 4491-4507.

Chien, M.-H., and C.-M. Wu, 2016: Representation of topography by partial steps using the immersed boundary method in a vector vorticity equation model (VVM). $J$. Adv. Model. Earth Syst., 8, 212-223.

Chou, C., and J. D. Neelin, 2004: Mechanisms of global warming impacts on regional tropical precipitation. $J$. Climate, 17, 2688-2701.

Chou, C., J. D. Neelin, C.-A. Chen, and J.-Y. Tu, 2009: Evaluating the "rich-get-richer" mechanism in tropical precipitation change under global warming. J. Climate, 22, 1982-2005.

Ciesielski, P. E., and R. H. Johnson, 2006: Contrasting characteristics of convection over the northern and southern South China Sea during SCSMEX. Mon. Wea. Rev., 134, 1041-1062.

Dee, D. P., S. M. Uppala, A. J. Simmons, P. Berrisford, P. Poli, S. Kobayashi, U. Andrae, M. A. Balmaseda, G. Balsamo, P. Bauer, P. Bechtold, A. C. M. Beljaars, L. van de Berg, J. Bidlot, N. Bormann, C. Delsol, R. Dragani, M. Fuentes, A. J. Geer, L. Haimberger, S. B. Healy, H. Hersbach, E. V. Hólm, L. Isaksen, P. Kållberg, M. Köhler, M. Matricardi, A. P. McNally, B. M. Monge-Sanz, J.-J. Morcrette, B.-K. Park, C. Peubey, P. de Rosnay, C. Tavolato, J.-N. Thepaut, and F. Vitart, 2011: The ERA-Interim reanalysis: Configuration and performance of the data assimilation system. Quart. J. Roy. Meteor. Soc., 137, 553-597.

Hagihara, Y., H. Okamoto, and R. Yoshida, 2010: Development of a combined CloudSat-CALIPSO cloud mask to show global cloud distribution. J. Geophys. Res., 115, D00H33, doi:10.1029/2009JD012344.

Hamada, A., Y. Murayama, and Y. N. Takayabu, 2014: Regional characteristics of extreme rainfall extracted from TRMM PR measurements. J. Climate, 27, 81518169.

Hassim, M. E. E., T. P. Lane, and W. W. Grabowski, 2016: The diurnal cycle of rainfall over New Guinea in convection-permitting WRF simulations. Atmos. Chem. Phys., 16, 161-175.

Holloway, C. E., and J. D. Neelin, 2010: Temporal relations of column water vapor and tropical precipitation. $J$. Atmos. Sci., 67, 1091-1105.

Houze, R. A., Jr., 2004: Mesoscale convective systems. Rev. Geophys., 42, RG4003, doi:10.1029/2004RG000150.

Houze, R. A., Jr., S. G. Geotis, F. D. Marks, Jr., and A. K. West, 1981: Winter monsoon convection in the vicinity of north Borneo. Part I: Structure and time variation of the clouds and precipitation. Mon. Wea. Rev., 109, 1595-1614.

Huffman, G. J., R. F. Adler, D. T. Bolvin, and E. J. Nelkin, 2010: The TRMM multi-satellite precipitation analysis (TMPA). Satellite Rainfall Applications for Surface Hydrology. Gebremichael, M., and F. Hossain (eds.), Springer, 3-22. 
Iacono, M. J., J. S. Delamere, E. J. Mlawer, M. W. Shephard, S. A. Clough, and W. D. Collins, 2008: Radiative forcing by long-lived greenhouse gases: Calculations with the AER radiative transfer models. J. Geophys. Res., 113, D13103, doi:10.1029/2008JD009944.

Ichikawa, H., and T. Yasunari, 2006: Time-space characteristics of diurnal rainfall over Borneo and surrounding oceans as observed by TRMM-PR. J. Climate, 19, 1238-1260.

Johnson, R. H., and D. L. Priegnitz, 1981: Winter monsoon convection in the vicinity of north Borneo. Part II: Effects on large-scale fields. Mon. Wea. Rev., 109, 1615-1628.

Johnson, R. H., S. L. Aves, P. E. Ciesielski, and T. D. Keenan, 2005: Organization of oceanic convection during the onset of the 1998 East Asian summer monsoon. Mon. Wea. Rev., 133, 131-148.

Jung, J.-H., and A. Arakawa, 2008: A three-dimensional anelastic model based on the vorticity equation. Mon. Wea. Rev., 136, 276-294.

Kanamori, H., T. Yasunari, and K. Kuraji, 2013: Modulation of the diurnal cycle of rainfall associated with the MJO observed by a dense hourly rain gauge network at Sarawak, Borneo. J. Climate, 26, 4858-4875.

Krueger, S. K., Q. Fu, K. N. Liou, and H.-N. S. Chin, 1995: Improvements of an ice-phase microphysics parameterization for use in numerical simulations of tropical convection. J. Appl. Meteor, 34, 281-287.

Kummerow, C., J. Simpson, O. Thiele, W. Barnes, A. T. C. Chang, E. Stocker, R. F. Adler, A. Hou, R. Kakar, F. Wentz, P. Ashcroft, T. Kozu, Y. Hong, K. Okamoto, T. Iguchi, H. Kuroiwa, E. Im, Z. Haddad, G. Huffman, B. Ferrier, W. S. Olson, E. Zipser, E. A. Smith, T. T. Wilheit, G. North, T. Krishnamurti, and K. Nakamura, 2000: The status of the tropical rainfall measuring mission (TRMM) after two years in orbit. J. Appl. Meteor, 39, 1965-1982.

Kuo, K.-T., and C.-M. Wu, 2019: The precipitation hotspots of afternoon thunderstorms over the Taipei basin: Idealized numerical simulations. J. Meteor. Soc. Japan, 97, 501-517.

Kuo, Y.-H., J. D. Neelin, and C. R. Mechoso, 2017: Tropical convective transition statistics and causality in the water vapor-precipitation relation. J. Atmos. Sci., 74, 915-931.

Liebmann, B., and C. A. Smith, 1996: Description of a complete (interpolated) outgoing longwave radiation dataset. Bull. Amer. Meteor. Soc., 77, 1275-1277.

Lin, P.-H., Y.-J. Yang, C.-H. Liu, S.-P. Hsu, J.-H. Yang, C.-H. Wu, C.-K. Yu, S. Jan, and C.-H. Sui, 2016: Interaction of convection over the maritime continent - SCS with large-scale flow: 2016 winter monsoon pre-experiment. Atmos. Sci., 44, 329-352 (in Chinese).

Lo, M.-H., and J. S. Famiglietti, 2011: Precipitation response to land subsurface hydrologic processes in atmospheric general circulation model simulations. J. Geophys.
Res., 116, D05107, doi:10.1029/2010JD015134.

Mapes, B. E., T. T. Warner, M. Xu, and A. J. Negri, 2003a: Diurnal patterns of rainfall in northwestern South America. Part I: Observations and context. Mon. Wea. Rev., 131, 799-812.

Mapes, B. E., T. T. Warner, and M. Xu, 2003b: Diurnal patterns of rainfall in northwestern South America. Part III: Diurnal gravity waves and nocturnal convection offshore. Mon. Wea. Rev., 131, 830-844.

Marchand, R., G. G. Mace, T. Ackerman, and G. Stephens, 2008: Hydrometeor detection using Cloudsat-An earth-orbiting 94-GHz cloud radar. J. Atmos. Oceanic Technol., 25, 519-533.

Mori, S., J. Hamada, Y. I. Tauhid, M. D. Yamanaka, N. Okamoto, F. Murata, N. Sakurai, H. Hashiguchi, and T. Sribimawati, 2004: Diurnal land-sea rainfall peak migration over Sumatera Island, Indonesian Maritime Continent, observed by TRMM satellite and intensive rawinsonde soundings. Mon. Wea. Rev., 132, 2021-2039.

Neelin, J. D., O. Peters, J. W. B. Lin, K. Hales, and C. E., Holloway, 2008: Rethinking convective quasi-equilibrium: Observational constraints for stochastic convective schemes in climate models. Philos. Trans. R. Soc. A, 366, 2581-2604.

Nesbitt, S. W., and E. J. Zipser, 2003: The diurnal cycle of rainfall and convective intensity according to three years of TRMM measurements. J. Climate, 16, 14561475.

Raymond, D. J., and D. J. Torres, 1998: Fundamental moist modes of the equatorial troposphere. J. Atmos. Sci., 55, 1771-1790.

Raymond, D. J., and Ž. Fuchs, 2007: Convectively coupled gravity and moisture modes in a simple atmospheric model. Tellus A, 59, 627-640.

Raymond, D. J., and Ž. Fuchs, 2009: Moisture modes and the Madden-Julian oscillation. J. Climate, 22, 30313046.

Reynolds, R. W., N. A. Rayner, T. M. Smith, D. C. Stokes, and W. Wang, 2002: An improved in situ and satellite SST analysis for climate. J. Climate, 15, 1609-1625.

Sobel, A. H., and C. S. Bretherton, 2003: Large-scale waves interacting with deep convection in idealized mesoscale model simulations. Tellus A, 55, 45-60.

Su, C.-Y., C.-M. Wu, W.-T. Chen, and J.-H. Chen, 2019: Object-based precipitation system bias in grey zone simulation: The 2016 South China Sea summer monsoon onset. Climate Dyn., 53, 617-630.

Sugiyama, M., 2009: The moisture mode in the quasi-equilibrium tropical circulation model. Part I: Analysis based on the weak temperature gradient approximation. J. Atmos. Sci., 66, 1507-1523.

Tsai, J.-Y., and C.-M. Wu, 2016: Critical transitions of stratocumulus dynamical systems due to perturbation in free-atmosphere moisture. Dyn. Atmos. Oceans, 76, $1-13$. 
Tsai, W.-M., and C.-M. Wu, 2017: The environment of aggregated deep convection. J. Adv. Model. Earth Syst., 9, 2061-2078.

Wang, B., LinHo, 2002: Rainy season of the Asian-Pacific summer monsoon. J. Climate, 15, 386-398.

Wang, B., LinHo, Y. Zhang, and M.-M. Lu, 2004: Definition of South China Sea monsoon onset and commencement of the East Asia summer monsoon. J. Climate, 17, 699-710.

Wang, B., F. Huang, Z. Wu, J. Yang, X. Fu, and K. Kikuchi, 2009: Multi-scale climate variability of the South China Sea monsoon: A review. Dyn. Atmos. Oceans, 47, 15-37.

Wapler, K., and T. P. Lane, 2012: A case of offshore convective initiation by interacting land breezes near Darwin, Australia. Meteorol. Atmos. Phys., 115, 123-137.

Warner, T. T., B. E. Mapes, and M. Xu, 2003: Diurnal patterns of rainfall in northwestern South America. Part II: Model simulations. Mon. Wea. Rev., 131, 813-829.

Williams, M., and R. A. Houze, Jr., 1987: Satellite-observed characteristics of winter monsoon cloud clusters. Mon. Wea. Rev., 115, 505-519.

Wu, C.-M., and A. Arakawa, 2011: Inclusion of surface topography into the vector vorticity equation model (VVM). J. Adv. Model. Earth Syst., 3, M06002, doi: 10.1029/2011MS000061.

Wu, C.-M., and A. Arakawa, 2014: A unified representation of deep moist convection in numerical modeling of the atmosphere. Part II. J. Atmos. Sci., 71, 2089-2103.

Wu, C.-M., M.-H. Lo, W.-T. Chen, and C.-T. Lu, 2015:
The impacts of heterogeneous land surface fluxes on the diurnal cycle precipitation: A framework for improving the GCM representation of land-atmosphere interactions. J. Geophys. Res., 120, 3714-3727.

Wu, C.-M., H.-C. Lin, F.-Y. Cheng, and M.-H. Chien, 2019: Implementation of the land surface processes into a vector vorticity equation model (VVM) to study its impact on afternoon thunderstorms over complex topography in Taiwan. Asia-Pacific J. Atmos. Sci., 55, 701-717.

Yanase, A., K. Yasunaga, and H. Masunaga, 2017: Relationship between the direction of diurnal rainfall migration and the ambient wind over the Southern Sumatra Island. Earth Space Sci., 4, 117-127.

Yang, G.-Y., and J. Slingo, 2001: The diurnal cycle in the tropics. Mon. Wea. Rev., 129, 784-801.

Yokoi, S., S. Mori, M. Katsumata, B. Geng, K. Yasunaga, F. Syamsudin, Nurhayati, and K. Yoneyama, 2017: Diurnal cycle of precipitation observed in the western coastal area of Sumatra Island: Offshore preconditioning by gravity waves. Mon. Wea. Rev., 145, 37453761 .

Yu, J.-Y., and J. D. Neelin, 1994: Modes of tropical variability under convective adjustment and the MaddenJulian oscillation. Part II: Numerical results. J. Atmos. Sci., 51, 1895-1914.

Yuan, J., and R. A. Houze, Jr., 2010: Global variability of mesoscale convective system anvil structure from A-train satellite data. J. Climate, 23, 5864-5888. 